\title{
A distinct autosomal recessive ocular anomaly in Chaharborj, Islamic Republic of Iran
}

H. Khakshoor, ${ }^{7}$ R. Daneshvar, ${ }^{7}$ T. Banaee, ${ }^{7}$ S.A. Tabatabaee Yazdi, ${ }^{2}$ M. Hasanzadeh Nazarabadi, ${ }^{3}$ M. Moosavi, F. Tavassolit and R. Mahdavi ${ }^{4}$

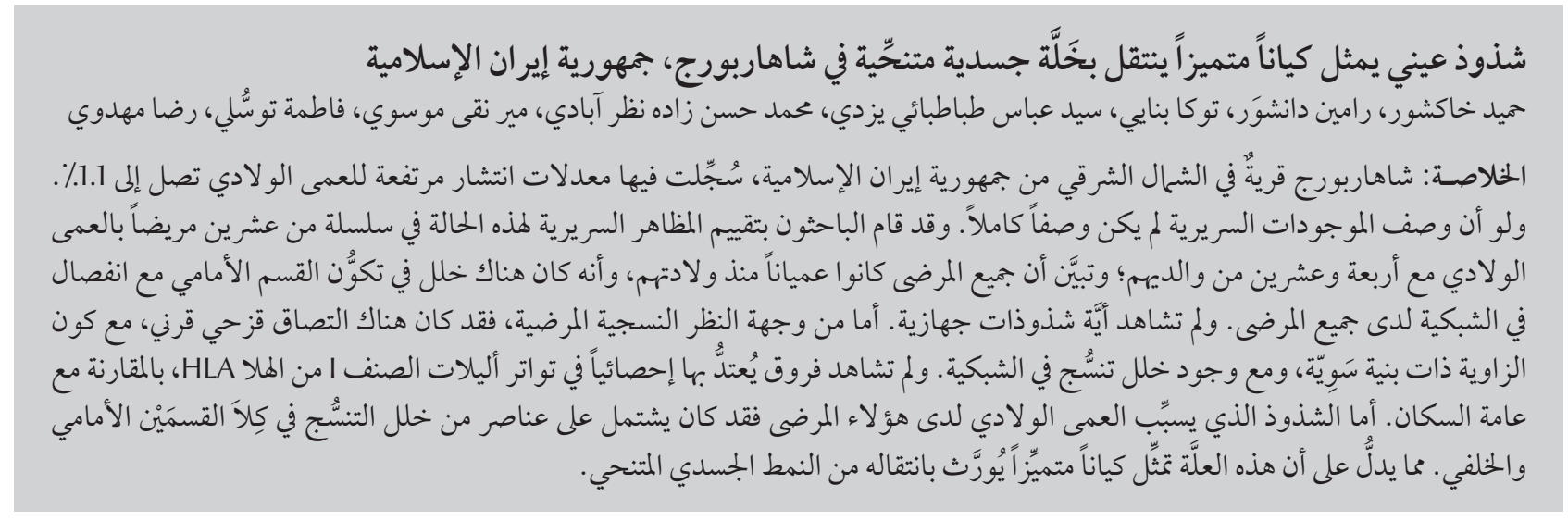

ABSTRACT In Chaharborj, a village in north-eastern of the Islamic Republic of Iran, a high prevalence of congenital blindness (1.1\%) has been reported. The clinical findings have not been fully described. We therefore assessed the clinical aspects of this condition in a case series of 20 congenitally blind patients and 24 of their parents. All patients had been blind since birth. There was anterior segment dysgenesis and retinal non-attachment in all patients. There were no systemic anomalies. Histopathologically, there was iridocorneal adhesion, normal angle structure and retinal dysplasia. No significant difference was found in the frequency of different HLA class I alleles compared with the general population. The anomaly causing congenital blindness in these patients has components of both anterior and posterior segment dysgenesis. It appears to be a distinct entity with an autosomal recessive pattern of inheritance.

Une anomalie oculaire autosomique récessive particulière à Chahar Borj (République islamique d'Iran)

RÉSUMÉ Une forte prévalence de cécité congénitale (1,1\%) a été rapportée à Chahar Borj, un village du nordest de la République islamique d'Iran, mais les résultats cliniques n’ont pas été complètement décrits. Nous avons donc évalué les aspects cliniques de cette pathologie à partir d'une série de 20 patients atteints de cécité congénitale et de 24 de leurs parents. Tous les patients souffraient de cécité depuis leur naissance, et présentaient une dysgénésie du segment antérieur de l'œil, de même qu'un décollement de la rétine. Aucune anomalie systémique n’a été observée. L'examen histopathologique a révélé une adhérence irido-cornéenne, un angle normal et une dysplasie rétinienne. Aucune différence significative n'a été retrouvée dans la fréquence des allèles HLA de classe I par rapport à la population générale. L'anomalie à l'origine de la cécité congénitale chez ces patients comportait une dysgénésie du segment antérieur comme du segment postérieur de l'œil. II semble que ce soit une pathologie distincte avec un mode de transmission autosomique récessif.

${ }^{7}$ Khatam Anbia Eye Hospital, Eye Research Center ofMashhad University ofMedical Sciences, Mashhad, Islamic Republic of Iran (Correspondence to R. Daneshvar: radaneshvar@gmail.com).

${ }^{2}$ Ghaem Hospital; ${ }^{4}$ Imam Reza Hospital, Mashhad University of Medical Sciences, Mashhad, Islamic Republic of Iran.

${ }^{3}$ Department of Medical Genetics, Mashhad University of Medical Sciences, Mashhad, Islamic Republic of Iran.

Received: 21/06/09; accepted: 04/05/10 


\section{Introduction}

Visual impairment imposes significant social and economic burdens worldwide. According to estimates based on the 2002 global population, more than 161 million people were visually impaired, 124 million had low vision and 37 million were blind $[1,2]$. The Vision 2020 project, a global initiative, was launched in 1999 with an aim to eliminate avoidable blindness by 2020 . Accurate information on the prevalence and causes of visual impairment may help international health organizations prioritize resources and develop appropriate human resources and infrastructures. Such information would help in the development of screening programmes and the identification of people with an increased risk of diseases $[3,4]$.

Developing countries bear a major burden of the condition; $90 \%$ of blind individuals [5] live in developing countries. The burden of blindness is particularly severe in Asia. In accordance with the World Health Organization's (WHO) Vision 2020 objectives, accurate ophthalmic epidemiologic data from Asia are needed to optimize the allocation of limited resources [6].

The prevalence of all cases of blindness from different parts of the world has been reported to range from $0.4 \%$ to $1.78 \%$. A small fraction of these occur during childhood $[7,8]$, and a small proportion of these figures are due to congenital cases [9].

The reported prevalence of childhood blindness from different countries across the world ranges from 0.1 to 1.1 per 1000 population $[10,11]$. In Chaharborj, a village in north-eastern of Islamic Republic of Iran, the prevalence of congenital blindness is $1.1 \%$, with a carrier frequency of about $20 \%$. This high rate has attracted the attention of investigators to find its etiology. Ghiasvand and colleague found an autosomal recessive pattern of inheritance among the affected patients of this village [12]. They mapped the delinquent gene to the chromosomal band 10q21 [13,14]. They considered that blindness was due to an autosomal recessive form of nonsyndromal congenital retinal nonattachment (NCRNA). However, as the clinical findings in affected individuals have not been fully described previously and have considerable differences with previous description of NCRNA, we aimed to determine the clinical aspects of this interesting ocular anomaly of combined anterior and posterior segment dysgenesis.

\section{Methods}

Twenty (20) congenitally blind patients born in Chaharborj participated in the study; 24 of their parents were also examined. The case-finding protocol started in 1994 and continued prospectively; however, due to healthcare interventions to reduce marriage among co-inhabitants of the district, the number of cases with classic findings of disease reduced steadily. General physical examination was done and included vital signs, height, body weight and system-based examination, particularly of the genitourinary, musculoskeletal and neurological systems, as well as ophthalmic examination, including visual acuity testing when possible, Goldmann applanation tonometry, biomicroscopy, dilated indirect binocular ophthalmoscopy, axial length measurement (Topcon ES-100, Japan) and B-scan ultrasonography (Alcon ultrascan digital B-1000, United States of America).

No examination was done under general anaesthesia except in 1 case - 1 microphthalmic blind eye of a 4month-old infant undergoing general anaesthesia for another procedure was enucleated and examined with light microscopy after haematoxylin and eosin staining. Considering the progressive phthisis bulbi course of the disease and the limited chance for normal orbital development, the Ethical Committee approved the procedure and the parents provided a separate informed consent form.

HLA class I \& II typing was done using microcytotoxicity techniques as described previously [15].

Mashhad University of Medical Sciences Ethics Committee approval was obtained for the study. All of the patients or their parents or legal guardians gave consent to be included in the study. The research adhered strictly to the tenets of the Declaration of Helsinki.

\section{Results}

Twenty patients ( 9 females and 11 males), with an age range of 4 months to 31 years (mean 10.4 years) were examined. All the patients had been blind since birth according to the history given by the parents. The early features suggesting blindness had been smallness of the globes, presence of corneal opacity and inattention to light.

All the patients had microphthalmia and nystagmus. Visual acuity of both eyes was no light perception (NLP) in cooperative patients. Very young children, unable to cooperate for routine visual acuity testing, also showed no attention to the bright light of the indirect ophthalmoscope. Intraocular pressure was normal in all those cooperating with the examination. The microscopical findings are summarized in Table 1. Corneal opacity, with or without iridocorneal adhesion, was present in 19 eyes (47.5\%). Another common finding was the presence of iridocorneal adhesions in 1 or multiple points (up to 10 points) in 17 eyes (42.5\%) (Figure 1). These adhesions were either central or peripheral and their area varied from a small spot to large areas approaching as much as one-third of the cornea. Shallow to flat anterior chamber (29 eyes, 72.5\%) along with posterior synechia (29 eyes, $72.5 \%$ ) were the most common 


\begin{tabular}{|c|c|c|c|c|c|c|c|c|c|c|}
\hline Case no. & Sex/Age & AL & $\mathrm{CO}$ & SAC & IH & PS & $\begin{array}{l}\text { Pupil } \\
\text { NV }\end{array}$ & CAT & $\begin{array}{l}\text { Lens } \\
\text { NV }\end{array}$ & Comment \\
\hline \multirow{2}{*}{1} & \multirow{2}{*}{$\mathrm{M} / 6 \mathrm{mo}$} & & & \multirow[t]{2}{*}{$x$} & & $x$ & & \multicolumn{2}{|l|}{$x$} & \multirow[t]{2}{*}{ Phthisical, enucleated } \\
\hline & & & & & & $x$ & & $x$ & & \\
\hline \multirow{2}{*}{2} & \multirow{2}{*}{$\mathrm{F} / 9 \mathrm{mo}$} & & & \multirow[t]{2}{*}{$x$} & & $x$ & & \multicolumn{2}{|l|}{$x$} & \\
\hline & & & & & & $x$ & & $x$ & & \\
\hline \multirow{2}{*}{3} & \multirow{2}{*}{$\mathrm{M} / 13 \mathrm{mo}$} & & & & & $x$ & & & & Vitreous organization \\
\hline & & & & & & $x$ & & & & Vitreous organization \\
\hline \multirow{2}{*}{4} & \multirow{2}{*}{$\mathrm{M} / 28 \mathrm{mo}$} & & & & & & & & & Normal anterior segment \\
\hline & & & & & & & & & & Normal anterior segment \\
\hline \multirow{2}{*}{5} & \multirow{2}{*}{$\mathrm{F} / 3 \mathrm{y}$} & & $x$ & $x$ & $x$ & $x$ & & & $x$ & \\
\hline & & & $x$ & $x$ & $x$ & $x$ & & & $x$ & \\
\hline \multirow{2}{*}{6} & \multirow{2}{*}{$M / 3 y$} & & & $x$ & $x$ & $x$ & & & & \\
\hline & & & & $x$ & $x$ & $x$ & & & & \\
\hline \multirow[t]{2}{*}{7} & \multirow[t]{2}{*}{$\mathrm{F} / 6 \mathrm{y}$} & $x$ & & $x$ & & & & $x$ & & $\begin{array}{l}\text { Multiple AL, posterior } \\
\text { embryotoxon }\end{array}$ \\
\hline & & $x$ & & $x$ & & & & $x$ & & \\
\hline \multirow{2}{*}{8} & \multirow{2}{*}{$M / 6 y$} & & $x$ & $x$ & & $x$ & & & $x$ & \\
\hline & & & $x$ & $x$ & & $x$ & & & $x$ & \\
\hline \multirow{2}{*}{9} & \multirow{2}{*}{$M / 7 y$} & $x$ & $x$ & $x$ & & $x$ & & & $x$ & \\
\hline & & & $x$ & $x$ & & $x$ & & $x$ & & \\
\hline 10 & M/8y & $x$ & $x$ & $x$ & & $x$ & & & & Persistent papillary membrane \\
\hline 10 & $101 / 0 y$ & $x$ & & $x$ & & & & & & Corectopia \\
\hline 11 & $M / 8 v$ & $x$ & & $x$ & & $x$ & & $x$ & & Corectopia \\
\hline$\pi$ & $101 / 0 y$ & & & & & $x$ & & $x$ & & \\
\hline 12 & $F / 10 y$ & $x$ & $x$ & $x$ & $x$ & $x$ & & $x$ & & Peripheral anterior synechia \\
\hline 12 & r/10y & & & $x$ & & & & $x$ & & \\
\hline 13 & $M / 12 y$ & & & & & & & & & Normal anterior segment \\
\hline & & & & & & $x$ & & $x$ & & \\
\hline 14 & E $/ 2$ & $x$ & $x$ & $x$ & & $x$ & & & $x$ & Band keratopathy, multiple AL \\
\hline 14 & r/12y & $x$ & $x$ & $x$ & & $x$ & & & $x$ & Band keratopathy \\
\hline & $F / 4 y$ & $x$ & $x$ & $x$ & $x$ & $x$ & & $x$ & & \\
\hline 15 & $5 / 14 y$ & $x$ & $x$ & $x$ & $x$ & $x$ & & & & \\
\hline 16 & $F / 14 y$ & & $x$ & $x$ & & & $x$ & & $x$ & Spheroid degeneration \\
\hline & (1) & & $x$ & $x$ & & & $x$ & & $x$ & Spheroid degeneration \\
\hline 17 & $\mathrm{~F} / 16 \mathrm{y}$ & $x$ & $x$ & $x$ & & & $x$ & & $x$ & \\
\hline 17 & $1 / 70 y$ & $x$ & $x$ & $x$ & & & $x$ & & $x$ & \\
\hline 18 & $M / 35 v$ & $x$ & $x$ & $x$ & & $x$ & & & $x$ & $\begin{array}{l}\text { Superficial \& deep corneal } \\
\text { vascularization }\end{array}$ \\
\hline 10 & ivi/ suy & $x$ & $x$ & $x$ & & $x$ & & & $x$ & $\begin{array}{l}\text { Superficial \& deep corneal } \\
\text { vascularization }\end{array}$ \\
\hline 19 & $M / 28 y$ & $x$ & $x$ & $x$ & $x$ & $x$ & & $x$ & & $\begin{array}{l}\text { Spheroid degeneration, } \\
\text { peripheral anterior synechia }\end{array}$ \\
\hline & & $X$ & & & $x$ & $x$ & & $x$ & & Pupillary membrane \\
\hline & & & & $x$ & & $x$ & & & & Pupillary membrane \\
\hline 20 & $\mathrm{~F} / 31$ y & & & & & $x$ & & & & $\begin{array}{l}\text { Pupillary membrane, posterior } \\
\text { embryotoxon }\end{array}$ \\
\hline Overall fre & lency (\%) & 42.5 & 47.5 & 72.5 & 22.5 & 72.5 & 10.0 & 40.0 & 32.5 & \\
\hline
\end{tabular}

For each case, findings for the the right eye are given in the first row and for the left eye in the second row.

$A L=$ adherent leukoma; $C O=$ corneal opacity; $S A C$ : shallow anterior chamber; $I H=$ iris hypoplasia; $P S=$ posterior synechia; $N V=n o t$ visible; $M=$ male; $F=$ female 

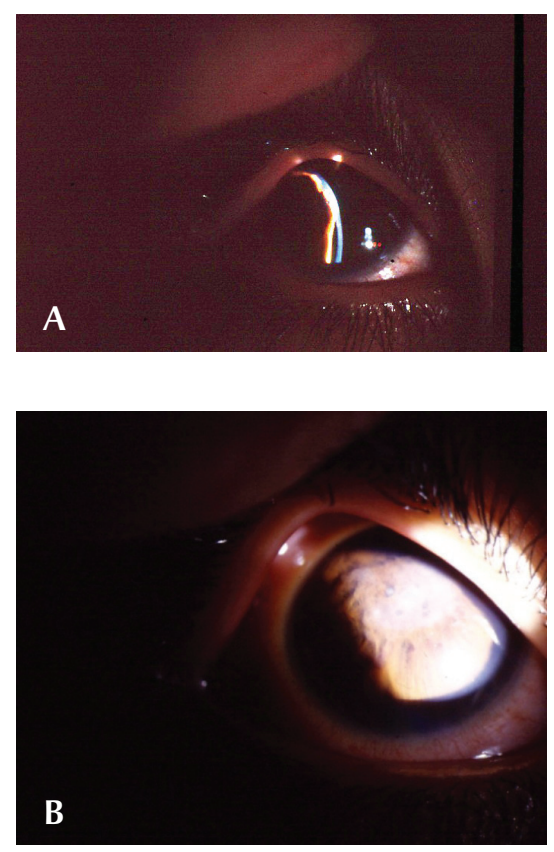

Figure 1 Iridocorneal adhesion at 1 site (A) and multiple sites (B)

anterior segment manifestation of the disease (Figure 2). Other findings were spheroid degeneration or calcific band keratopathy ( 5 eyes, $12.5 \%$ ), patches of iris hypoplasia (9 eyes, $22.5 \%$ ), persistent pupillary membrane (4 eyes, $10 \%$ ),
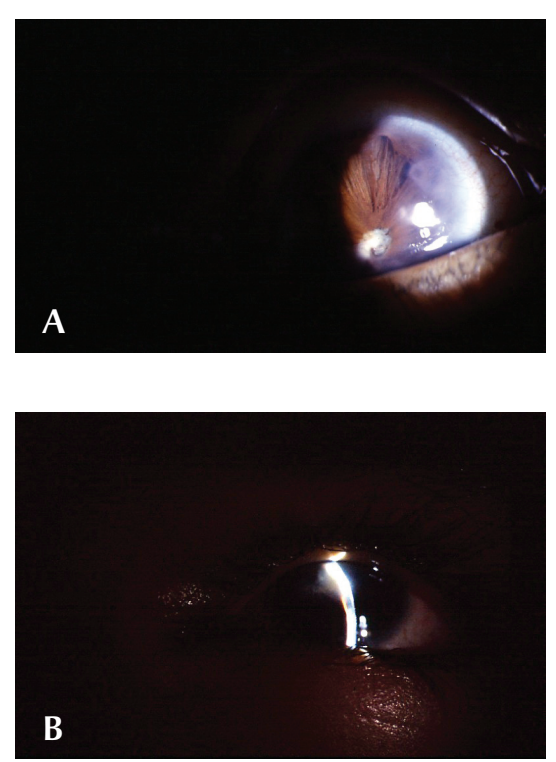

Figure 2 Iris hypoplasia, cataract, corectopia, and posterior embryotoxon (A), and shallow anterior chamber with corneal opacity (B) were among the anterior segment manifestations of the anomaly posterior embryotoxon (2 eyes, 5\%), and normal anterior segment (3 eyes, $7.5 \%)$. The lens was visible in 27 eyes, 16 of them being cataractous ( $40 \%$ of all eyes). Corneal opacity precluded visualization of the lens in 13 eyes (32.5\%).

The fundus was visible in 4 eyes. There was total retinal elevation in 3 eyes accompanied by optic atrophy in 2. One sector of the retina was attached and had pigmentary changes in 1 eye.

B-scan ultrasonography was done for 17 patients (34 eyes). There was retinal elevation (possibly nonattachment) along with dense retrolental echogenicities in 33 eyes ( $82.5 \%$ ) (Figure 3). One eye had phthisis bulbi without a visible vitreous cavity. All of the 34 eyes had short echo-times on axial length measurement (range 9-18 mm).

In one patient (case 1), one eye was enucleated. There were iridocorneal adhesions on histopathological examination of the enucleated globe. Ciliary processes were elongated in some sections with hyperplasia of the nonpigmented epithelium (Figure 4). Anterior chamber angle and lens did not show any significant abnormalities. A retrolental fibroglial tissue was present and extended to the optic disk. The retina was dysplastic and totally detached. The retina showed a high degree of differentiation with nuclear stratifications in 2 layers (Figure 5) in some sections. Dysplastic rosettes with 1 or 2 rows of nuclei were also present (Figure 6). The retina merged with the fibroglial retrolental tissue centrally. The subretinal fluid was eosinophilic with many cholesterol clefts and was bordered by foamy macrophages. The retinal pigment epithelium showed hyperplasia in some areas.

Ophthalmic examination of parents was unremarkable. Systemic examinations of both patients and parents were normal.

HLA-A3 (35.5\%), A4 (41\%), B5 (41.2\%), DR5 (47\%) and DR7 (47\%) were the most frequent antigenic types in our patients. Frequencies of different HLA class I antigens in our patients did not differ significantly from those of the general population of Khorasan province (chi-squared $P>0.05$ ) [16].

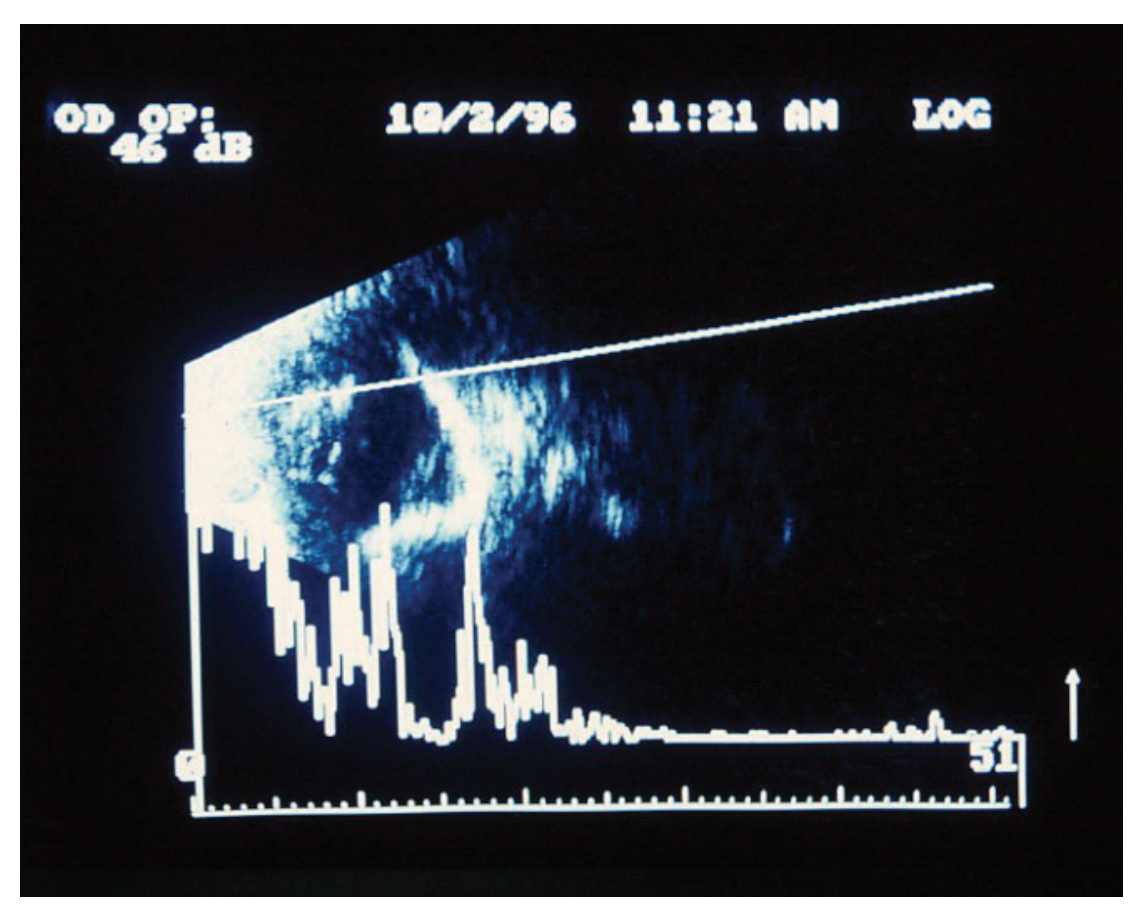

Figure 3 Ultrasonography showing the presence of dense retrolental echogenicities and retinal elevation 


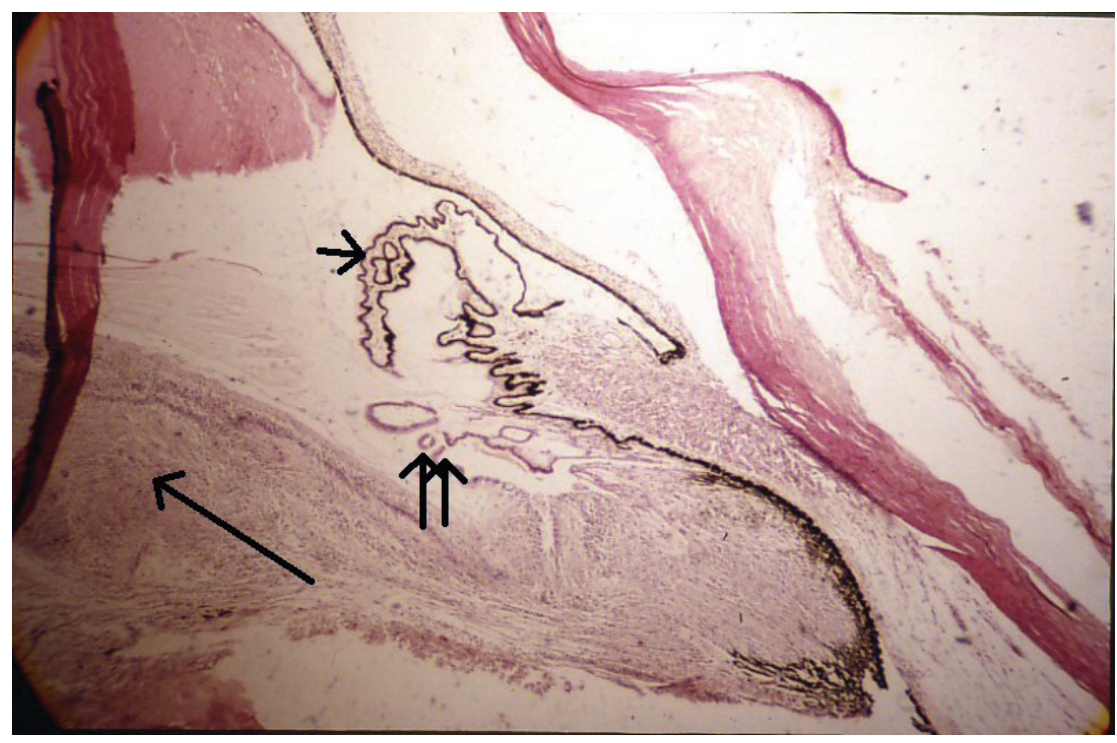

Figure4 Histopathological specimen showing retrolental fibroglial tissue (long arrow), elongated ciliary process (short arrow) and hyperplasia of the nonpigmented epithelium of the ciliary body (double arrow). There is an artifact overlay of the cornea on the lens and retrolental fibroglial tissue in the left part of the specimen and artifact ciliary body separation from the scleral spur (H\&E stain $40 \times)$

\section{Discussion}

In this series of congenitally blind patients, we describe the clinical features of a distinct ocular anomaly with mixed anterior and posterior segment

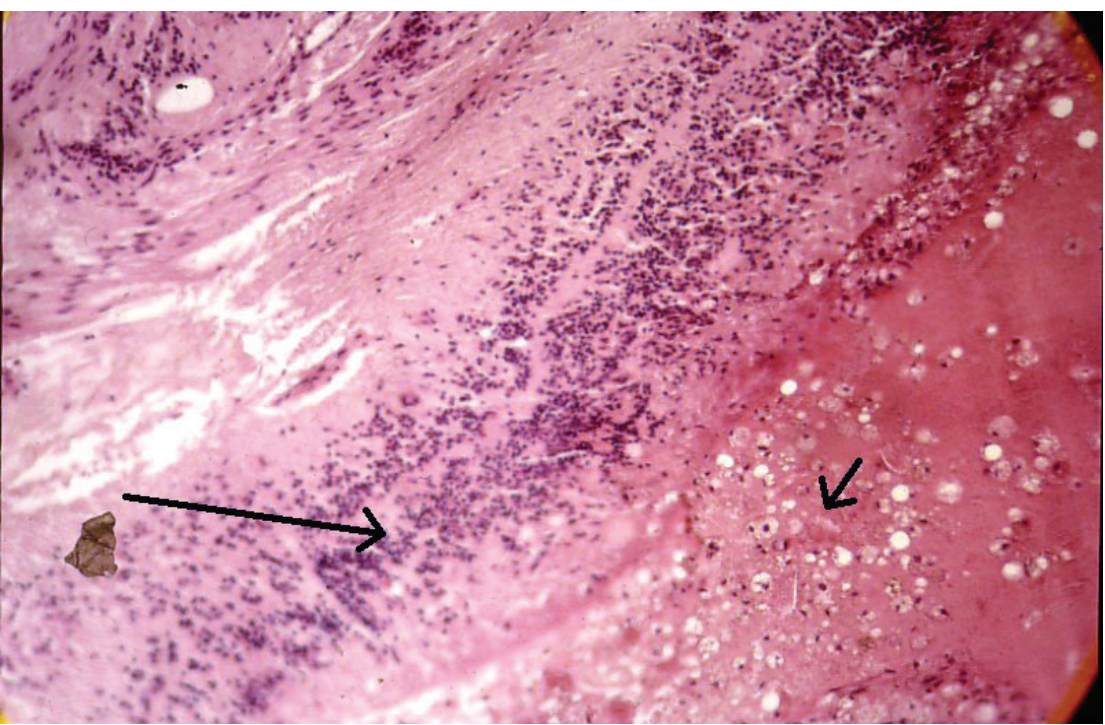

Figure 5 Section through the detached (non-attached) retina shows some differentiation toward maturation with the presence of 2 nuclear layers (long arrow). Subretinal fluid is densely eosinophilic and crowded by foam cells (short arrow) (H\&E stain 40×) differences from the known causes of childhood blindness. Our findings have been presented at several regional and international meetings; but have never been previously published in an article.

The anterior segment findings in our patients resembles Peter's anomaly. However, the main features of Peter's anomaly are posterior corneal defect with overlying corneal opacity, iris adhesion to the edge of the corneal defect and corneolenticular adhesion or cataract. Several accompanying abnormalities including persistent hyperplasic primary vitreous (PHPV), persistent tunica vasculosa lentis and retinal dysplasia have been reported $[17,18]$. This picture has the following clear discrepancies with our patients.

- Some of the eyes in our series had near normal anterior segments (Table 1) and it seems that the posterior segment involvement of the anomaly is the major component. However, in Peter's anomaly, posterior corneal defects are usually associated with posterior segment anomalies in the more severe forms with cataract and corneolenticular adhesions [18].

- The corneal opacity in Peter's anomaly is central or paracentral [18], while in some of our patients the corneal opacity was peripheral (Figure 2).

- When cataract is present in Peter's anomaly, it is usually accompanied by corneolenticular adhesion [18]. In spite of the presence of cataract in $40 \%$ of the eyes in our series, no corneolenticular adhesions were seen.

- Up to $50 \%$ of patients with Peter's anomaly develop glaucoma [18], whereas no patient in our series had buphthalmos and none of the older patients who had intraocular pressure measurements had elevated intraocular pressure or glaucomatous optic nerve damage. Therefore, we believe that although the anterior segment findings of these patients have some similarities with Peter's anomaly, they could be different entities. 


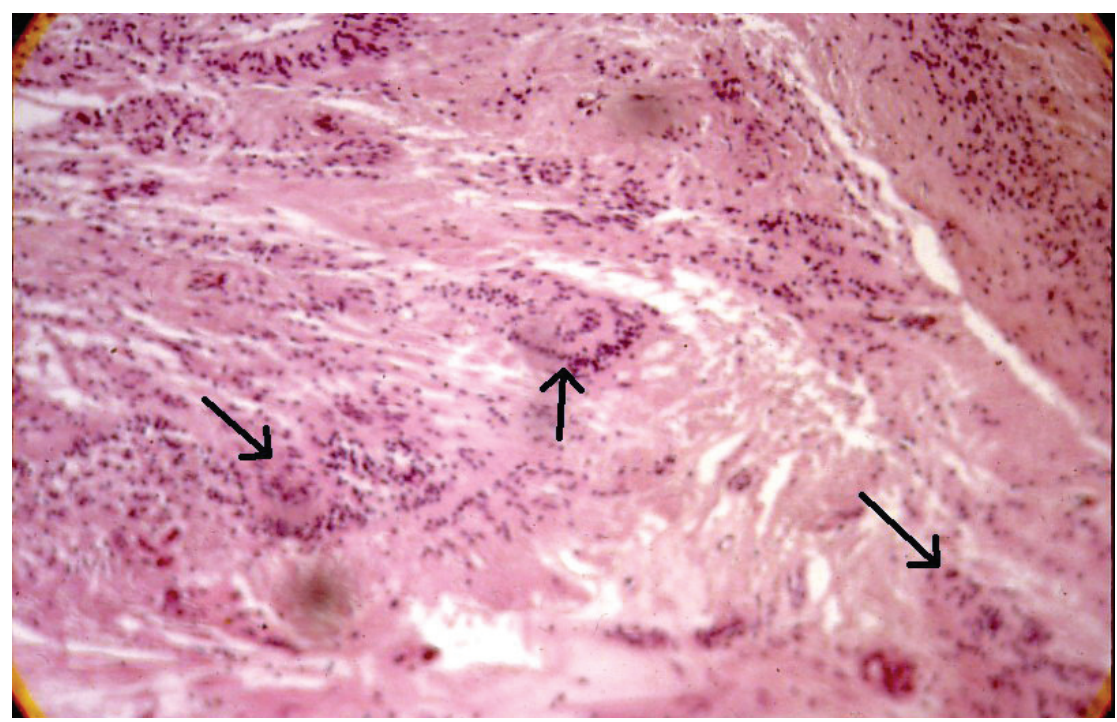

Figure 6 Section through the retrolental tissue containing dysplastic rosettes of immature retina with 2 rows of nuclei (arrows) (H\&E stain $40 \times$ ).

Norrie's disease is another known cause of childhood blindness; however, the anomaly in our patients is also different from that of Norrie's disease in the following ways:

- Norrie's disease is an X-linked recessive disorder while the pattern of inheritance in our series is autosomal recessive [19].

- Accompanying systemic malformations have been reported in Norrie's disease but were not found in our patients [20]

- Progression of anterior segment lesions and retinal detachment occur after birth in Norrie's disease [21], but as stated before, all our patients had had the anomalies since birth (recognized by parents from the presence of microphthalmia and corneal opacity).

Another possible differential diagnosis would be persistent hyperplasic primary vitreous (PHPV). Despite the presence of some similarities in the ophthalmic findings and histopathology between the constellation of findings in our patients and PHPV, bilaterality and the heritable nature of the malformations in the current series suggests the different nature of the two entities [17].
Retinal dysplasia is a common endpoint of many factors acting upon the immature retina, including trisomy 13, intrauterine infections, trauma, use of lysergic acid diethylamide (LSD) by the mother during pregnancy, and genetic factors. Retinal dysplasia may be accompanied by systemic or other ocular malformations (e.g. PHPV, failure of development of the secondary vitreous, elongated ciliary processes, microphthalmia, fetal type filtration angle, Peter's anomaly, and uveal and optic nerve coloboma) [21-23].

Four pathogenetic mechanisms have been suggested for retinal dysplasia [22].

- Hyperplastic extension of the retina into abnormal sites away from its pigment epithelium.

- Secondary to detachment of retina from the pigment epithelium

- Occurring in an otherwise normal location over areas devoid of pigment epithelium (such as a coloboma)

- An in situ dysplastic process.

The role of the retinal pigment epithelium in normal development of the immature retina has been stressed previously $[21,22]$. Absence of vitreous and presence of concentrated subretinal fluid with cholesterol crystals in the histopathological specimens of the enucleated eye of case 1 in the current series points to the second pathogenetic mechanism, namely retinal detachment, in this case as the possible mechanism for retinal dysplasia.

The following 4 types of dysplastic rosettes (ranked from more to less differentiated) have been recognized:

- Three-layer rosettes consisting of mature retina thrown into folds;

- Two-layer rosettes with an inner layer of photoreceptor-like cells surrounded by another layer of retinal cells;

- A single layer of neural cells arranged around a central lumen;

- Primitive single-layer rosette of neural cells around a tangle of central fibrils [21].

The dysplastic rosettes in our case mostly had 2 layers of nuclei. There were also at least 2 nuclear layers in sections with visible retinal layering. This means a moderate degree of differentiation and indicates the probability of an insult, probably a detachment occurring before completion of retinal layer differentiation (midterm) and after the retina has attained at least 2 rows of nuclei (7th week of gestation) [21].

Kaswan and coworkers [24] reported similar ocular findings (microphthalmia, absence of pupil, other iris malformations, absence of anterior chamber and lens, retinal detachment and retinal dysplasia) with an autosomal dominant pattern of inheritance in a herd of cattle. A similar anomaly including the above findings plus corneal opacity with autosomal recessive inheritance was found in dogs [25]. It seems that the affected gene in all these cases (mapped to chromosome band 10q21 in humans [14]) codes for a factor with a crucial direct or indirect role in ocular organogenesis (maintaining retinal attachment and normal anterior segment development).

The disease showed no associations with HLA class I, which implies that 
consanguineous marriages do not affect its occurrence. In autosomal recessive diseases, this happens only when the culprit gene is widely distributed in the population. Consanguineous marriage is an encouraged custom in Iranian villages. This, along with a language barrier, has resulted in the creation of a genetically closed population in Chaharborj, thus resulting in a wide distribution of the abnormal gene in this population. It seems that the only way to prevent occurrence of new cases of the disease is by encouraging people of the village to marry persons outside the district; indeed, avoiding consanguineous marriage would not be sufficient because of the widespread distribution of the gene in the village.

In summary, this disease seems to be a new entity with components of both anterior and posterior segment dysgenesis and with an autosomal recessive pattern of inheritance. We suggest the name "Chaharborj disease" to describe this unique complex of ocular involvement. To prevent occurrence of more affected cases, people of the village should not to marry persons from the same district.

\section{Acknowledgement}

This study was supported by a grant from the Ministry of Health and Medical Education of the Islamic Republic of Iran.

\section{Author note}

These findings were presented at the Sixth Iranian Congress of Ophthalmology, 1996, Tehran, Islamic Republic of Iran, and the XII Congress of the European Society of Ophthalmology, Stockholm, Sweden 1999.

\section{References}

1. Resnikoff $\mathrm{S}$ et al. Global data on visual impairment in the year 2002. Bulletin of the World Health Organization, 2004, 82:844-851.

2. Hennis AJ et al. Barbados Eye Studies Group. Nine-year incidence of visual impairment in the Barbados Eye Studies. Ophthalmology, 2009, 116:1461-1468.

3. Pararajasegaram R. VISION 2020-the right to sight: from strategies to action. American Journal of Ophthalmology, 1999, 128:359-360.

4. Huang $S$ et al. Prevalence and causes of visual impairment in Chinese adults in urban southern China. Archives of Ophthalmology, 2009, 127:1362-1367.

5. Chandra SR. Global blindness: VISION 2020: the right to sight. Archives of Ophthalmology, 2008, 126:1457.

6. Edussuriya $\mathrm{K}$ et al. The prevalence and causes of visual impairment in central Sri Lanka the Kandy Eye study. Ophthalmology, 2009, 116:52-56.

7. Tielsch JM. Statistics on the prevalence and causes of blindness and visual impairment in the population. In: Tasman W, Jeager EA, eds. Duane's clinical ophthalmology. Philadelphia, Lippincott Williams and Wilkins, 2004, Vol. 5.

8. Dandona L, Foster A. Patterns of blindness. In: Tasman W, Jeager EA, eds. Duane's clinical ophthalmology. Philadelphia, Lippincott Williams and Wilkins, 2004, Vol. 5.

9. Benezra D, Chirambo MC. Incidence and causes of blindness among the under 5 age group in Malawi. British Journal of Ophthalmology, 1977, 61:154-157.

10. Foster A, Gilbert C. Epidemiology of childhood blindness. Eye (London, England), 1992, 6:173-176.

11. Rojas JR, Lavado L, Echegaray L. Childhood blindness in Peru. Annals of Ophthalmology, 1990, 22:423-425.

12. Ghiasvand NM et al. High incidence of autosomal recessive nonsyndromal congenital retinal nonattachment (NCRNA) in an Iranian founding population. American Journal of Medical Genetics, 1998, 78:226-232.

13. Ghiasvand NM et al. Genetic fine mapping of the gene for nonsyndromic congenital retinal nonattachment. American Journal of Medical Genetics, 2000, 92:220-223.
14. Ghiasvand NM et al. Nonsyndromic congenital retinal nonattachment gene maps to human chromosome band 10 q21. American Journal of Medical Genetics, 2000, 90:165-168.

15. Aviner $\mathrm{Z}$ et al. Histocompatibility (HL-A) antigens and primary open-angle glaucoma. Tissue Antigens, 1976, 7:193-200.

16. Farid $\mathrm{R}$ et al. The distribution of class I HLA in 1000 normal individuals in Khorasan province. Medical Journal of the Islamic Republic of Iran, 1989, 3:43-45.

17. De Juan E Jr, Farr AK, Noorily S. Retinal detachment in infants. In: Ryan SJ, ed. Retina, 3rd ed. St. Louis, Mosby, 2001:2505.

18. Waring GO, Rodruiguez MM. Congenital and neonatal corneal abnormalities. In: Tasman W, Jeager EA, eds. Duane's foundations of clinical ophthalmology, rev. ed. Philadelphia, Lippincott Williams and Wilkins, 2004, Vol. 1.

19. Manschot WA. Pathology of hereditary conditions related to retinal detachment. Ophthalmologica, 1971, 162:223-234.

20. Verin PH, Comte P. Les anomalies oculaires d'origine congenital [Congenital ocular abnormalities]. L'Annee Therapeutique et Clinique en Ophtalmologie, 1986, 37:151-178.

21. Pagon RA, Speath GL. Congenital malformations of the eye. In: Tasman W, Jeager EA, eds. Duane's foundations of clinical ophthalmology, rev. ed. Philadelphia, Lippincott Williams and Wilkins, 2004, Vol. 1.

22. Silverstein AM, Osburn BI, Prendergast RA. The pathogenesis of retinal dysplasia. American Journal of Ophthalmology, 1971, 72:13-21.

23. Green WR. Retina. In: Spencer WH, ed. Ophthalmic pathology: an atlas and textbook, 2nd ed. Philadelphia, Saunders, 1985, Vol. 2.

24. Kaswan RL et al. Multiple hereditary ocular anomalies in a herd of cattle. Journal of the American Veterinary Medical Association, 1987, 191:97-99.

25. Bergsjø $\mathrm{T}$ et al. Congenital blindness with ocular developmental anomalies, including retinal dysplasia, in Doberman Pinscher dogs. Journal of the American Veterinary Medical Association, 1984, 184:1383-1386. 